\title{
Estratégia operária e neocapitalismo
}

Iram Jácome Rodrigues

Entre as questões suscitadas por Gorz, em seu livro Estratégia operária e neocapitalismo, há um tema que se sobressai: o local de produção como locus privilegiado do conflito entre capital e trabalho e das consequências organizativas propostas por este autor no que viria a ser uma nova estratégia de setores do movimento operário e do sindicalismo para os tempos de Welfare State.

Gorz inicia este seu trabalho contextualizando os aspectos mais gerais da relação entre socialismo e necessidade, e analisando as mudanças nas condições do capitalismo nos países centrais. Além disso, aponta que nesses países a extrema pobreza representaria apenas $20 \%$ da população. Com isto, tenta mostrar que ocorreu uma mudança fundamental naqueles países capitalistas mais desenvolvidos e, por essa razão, seria necessário repensar a estratégia do movimento operário e do sindicalismo nessas sociedades.

O socialismo nunca foi uma necessidade que se impusesse às massas com uma evidência fulgurante. Da revolta primitiva à vontade consciente de modificar a sociedade, nunca houve uma passagem imediata. O descontentamento dos trabalhadores, mesmo poderosamente organizados, a respeito de sua condição, nunca foi ultrapassado espontaneamente, visando uma colocação em questão da- 
quilo que, na organização geral da sociedade, tornava sua condição insuportável (Gorz, 1968, p. 9).

O autor faz, nesse estudo, uma reflexão sobre as transformações ocorridas no capitalismo pós-Segunda Guerra Mundial, notadamente nos anos de 1950 e início da década de 1960, no que diz respeito ao advento das novas condições em que se estruturava a produção capitalista.

Nesse sentido, esse movimento, que alguns convencionaram chamar de fordismo, foi um arranjo institucional estabelecido entre atores sociais diversos: as grandes empresas, os grandes sindicatos de trabalhadores e o Estado, com vistas a manter uma política econômica de tipo intervencionista (keynesiana) de proteção do mercado interno, alguma redistribuição da renda no âmbito desses países e uma atenuação, em um primeiro momento, do conflito capital/trabalho, se comparado com os conflitos de classe do século XIX até os anos de 1930.

Por isso,

[...] a recusa da sociedade perdeu, nos países capitalistas avançados, sua base natural. Enquanto a miséria - isto é, a privação do que é necessário para viver - era a condição da maioria, a necessidade de um desabamento revolucionário da sociedade podia vir automaticamente. Proletários e camponeses miseráveis não tinham necessidade, para se erguerem contra a ordem existente, de saber que outra sociedade pretendiam construir: o pior era o presente; não tinham nada a perder" (Idem).

Já nas condições desse novo capitalismo, mesmo subsistindo, a miséria não afetaria mais do que $20 \%$ de seus habitantes. Além disso, "esta população, além do mais, não é homogênea; está concentrada em certas regiões, em certas camadas que não são representativas de sua classe: pequenos camponeses de regiões [distantes], anciãos, desempregados, operários sem qualificação etc. Essas camadas são incapazes de se tornarem a agrupar para exercer uma ação decisiva sobre a sociedade e o Estado. Elas têm necessidades comuns, mas não um projeto referente às condições satisfatórias. Aí está uma primeira razão pela qual a miséria não pode mais servir de fundamento à luta pelo socialismo" (Idem).

O que está sendo mostrado por André Gorz é que as condições tanto sociais como políticas e econômicas se modificaram com o advento do Estado de Bem-Estar Social. Assim, o sistema econômico-político-social que emergiu após 1945, e que perdurou até inícios dos anos de 1970, em gran- 
de parte da Europa Ocidental, Estados Unidos e Japão, foi responsável por uma estabilidade que representou um incremento do bem-estar e aumento da riqueza em todos esses países. Nesse período, além desses aspectos e das altas taxas de crescimento econômico, a democracia e o Estado de BemEstar foram consolidados. Além disso, o Estado estimulou o desenvolvimento da atividade produtiva por meio de empréstimos e investimentos de longo prazo (cf. Rodrigues, 2006, p. 205).

Esses investimentos, em cada país, coordenados pelos Estados nacionais, embora assumissem alguns aspectos mais específicos, tinham como principal característica o processo de regulação do Estado no que tange à política macroeconômica, ou seja, uma decisiva intervenção do Estado na economia, com o objetivo de garantir o equilíbrio no campo econômico e a paz social no terreno político. Essas singularidades manifestavam-se em diferenças no padrão dos gastos públicos, na organização do sistema de bem-estar social e na presença maior ou menor do Estado nas decisões econômicas.

Desse modo, o conjunto de arranjos institucionais e corporativos constituiu-se na essência do que veio a ser denominado compromisso fordista e foi o principal ponto de apoio de sua estruturação. Vale dizer, Estado, grandes corporações e sindicatos passaram a ser a nova base desse regime de acumulação, cuja característica era a produção em massa de bens padronizados e em série.

Nesse aspecto, o fordismo representou um aprofundamento e ampliação do taylorismo na medida em que relacionou diretamente as mudanças que estariam ocorrendo no trabalho com transformações nas condições gerais de existência do trabalho assalariado. O conjunto dessas transformações, entre outros aspectos, levou à institucionalização das relações capital/ trabalho por meio de processos de negociação na empresa, nos setores econômicos e no plano nacional (cf. Aglietta, 1991).

Esse é o pano de fundo das reflexões de Gorz com relação às novas questões surgidas com o advento do Estado Sociale, diante desses temas, seria importante repensar a estratégia operária. Como observa Queiroz (2006, p. 65), "a reflexão desenvolvida por Gorz nas décadas de 1950 e 1960 esteve intimamente vinculada a um objetivo específico: pensar as características que o capitalismo assumia e propor novas alternativas de luta à classe trabalhadora. Para isso, o que mostra que recusava as usuais e dogmáticas concepções que eram naquele momento predominantes na esquerda marxista, analisou as várias esferas para, daí, mostrar que modificações o capitalismo pós-guerra trazia consigo. Este confronto ocorria também em relação às tradicionais formu- 
1. Para esta questão, ver tambémAmorim(2006). lações táticas e estratégicas do movimento dos trabalhadores, o qual se encontrava ainda fortemente influenciado pela perspectiva da III Internacional"1.

É nessa perspectiva que Gorz abordará a questão de uma nova estratégia para o movimento operário que parte, principalmente, das "reformas não reformistas". Assim, "esta luta não faz depender, de critérios capitalistas de racionalidade, a validade e o direito tradicionalmente consagrado pela necessidade" (Gorz, 1968, pp. 13-14). No entanto, Gorz assinala que para uma mudança na direção dessa estratégia seria necessária também outra correlação de forças. Os trabalhadores teriam que conquistar poderes ou afirmar poderes. Em outras palavras, seriam necessárias reformas de estruturas.

$\|$

Refletindo sobre um momento histórico de grandes transformações no capitalismo contemporâneo, o período que vai do final da Segunda Guerra Mundial até meados dos anos de 1960, Gorz explicita a demanda de controle do processo de trabalho que desempenha um papel central para seus argumentos. Pois essa demanda "adquire uma crescente significância em relação às lutas em torno dos salários e das horas de trabalho [...]. Enquanto a velha estratégia estava preocupada com demandas quantitativas, as demandas da nova estratégia são de natureza mais qualitativa. Ou seja, embora as demandas quantitativas ainda façam parte das principais preocupações da nova estratégia, sua importância parece diminuir à medida que o problema do controle operário se torna o núcleo das preocupações" (Silva, 2002, p. 104).

Assim, o tema do controle operário da produção, do controle do processo de trabalho, transforma-se para Gorz no cerne das mudanças necessárias para pensar a nova estratégia operária. Nesse aspecto, no contexto dos problemas tratados, o autor privilegia a questão do poder dos trabalhadores no âmbito da produção, do local de trabalho como central para a nova estratégia operária. Gorz observa que o proletariado, para que possa manter

[...] sua vocação de classe dirigente, deve primeiramente atacar a condição operária nos locais de trabalho porque é lá que, através das alienações mais diretas do trabalhador, como produtor e cidadão, a sociedade capitalista pode ser indiretamente contestada. E também porque é unicamente através da recusa consciente das relações opressivas de trabalho, através de uma ação consciente para submetê-las ao controle dos trabalhadores associados, através de uma vontade ininterrupta de autodetermi- 
nação independente das condições de trabalho, que a classe operária pode conservar ou afirmar permanentemente a autonomia de sua consciência de classe, a emancipação humana do trabalho como finalidade suprema" (Gorz, 1968, p. 46).

Neste caso, uma das questões subjacentes ao pensamento gorziano é trazer o local de trabalho para o centro da política. Na verdade, a "nova estratégia operária" vislumbrada por Gorz representa, ao mesmo tempo, uma crítica contundente à esquerda tradicional e, em certa medida, uma volta às raízes do movimento operário quando a questão do controle operário da produção, do trabalhador como produtor, estava em tela. Para Offe (1989, p. 176), por exemplo, "a unidade e coerência do trabalho" expressar-se-ia também no "orgulho coletivo dos produtores, uma consciência que reflexivamente expressa a teoria do valor do trabalho e o coloca (nas palavras da Crítica do Programa de Gotha) como 'a fonte de toda a riqueza e de toda a cultura"”.

O tema da organização dos trabalhadores em seus locais de trabalho está presente desde o início do movimento operário. O que leva à organização no interior das empresas é uma tendência generalizada por parte da mão de obra no sentido de adquirir algum poder de controle sobre as condições de trabalho. De outra parte, representa, também, um aspecto da resistência do operariado diante da organização capitalista do trabalho, bem como expressa o forte conflito entre capital e trabalho nos albores do capitalismo em decorrência, entre outros aspectos, das condições draconianas, à época, do trabalho fabril.

Segundo Sturmthal, do ponto de vista histórico, a organização operária no interior da empresa frequentemente precedeu o nascimento do sindicato como instrumento de negociação entre capital e trabalho. Ainda de acordo com esse autor, nos anos de 1848-1849, em decorrência da revolução na Alemanha, "uma das instituições propostas foi a formação de conselhos operários" que tinham como principal objetivo, entre outros aspectos, a resolução das disputas e reclamações internas, a regulamentação das relações entre capital e trabalho na empresa e a criação de organismos de bemestar social (cf. Sturmthal, 1971, pp. 33 e 111).

Esses aspectos podem nos ajudar a entender a recorrência às formas de organização de base quando de conflitos entre patrões e empregados. $\mathrm{Na}$ luta por seus direitos no interior do estabelecimento industrial, os trabalhadores procuram se organizar em seus locais de trabalho, nascendo assim a representação trabalhista nas empresas. Vale dizer, há uma tendência visível entre os assalariados, no bojo de grandes movimentos grevistas ou mesmo 
em greves isoladas, quando a questão já está disseminada na prática cotidiana das lutas operárias, de recorrer às organizações dos empregados nos locais de produção: chamem-se comissões de fábrica, comissões de empresa, conselhos operários etc.

Desse ponto de vista, quando Gorz enfatiza o tema do poder operário, significa, como observa Silva, a capacidade dos trabalhadores nas empresas de questionar mediante o controle operário da produção "as premissas [da] política de gestão da economia e das empresas capitalistas através do controle sobre os meios e as condições de sua formulação" (2002, p. 116).

Por isso, para que fosse possível construir essa nova estratégia seria necessário, segundo Gorz, relacionar as questões da produção, do cotidiano operário e da fábrica com o conjunto da sociedade:

A possibilidade de reunir em uma mesma perspectiva a condição operária no seio do processamento produtivo e no seio da sociedade, a possibilidade de fornecer dialeticamente motivos imediatos de descontentamento por razões profundas, inerentes às relações sociais e ao poder econômico e político, tal possibilidade surgiu de maneira mais ou menos explícita durante o desenrolar de todas as ações de massa do passado próximo. [...] Espontâneas ou demoradamente preparadas, todas essas ações punham em questão, de maneira explícita ou implícita, muitos outros problemas além do nível salarial. E demonstraram, cada uma a sua maneira, que, limitada unicamente ao aspecto salarial, a luta operária é imediatamente absorvida pela ondulação tática do patronato e do Estado; corre o perigo de atolar-se nas reivindicações de categorias e corporativas; mesmo vitoriosas sob este aspecto, arrisca-se a liquidar-se por uma derrota estratégica (Gorz, 1968, p. 38).

\section{É fundamental, de acordo com Gorz,}

[...] unir, na estratégia reivindicativa, a condição dos trabalhadores em seus locais de trabalho à sua condição no seio da sociedade. [...] Essa possibilidade é dada pela estreita conexão existente, na vida de todo trabalhador, entre as três dimensões essenciais de sua força de trabalho: 1. As relações de trabalho: isto é, a formação, a avaliação e a utilização da força de trabalho na empresa; 2. A finalidade do trabalho: isto é, as finalidades (ou produções) para as quais a força de trabalho é utilizada na sociedade; 3 . A reprodução da força de trabalho: isto é, a maneira e o local de vida do (2002, pp. 104-105). trabalhador, a maneira pela qual pode satisfazer suas necessidades naturais, profissionais, humanas (Idem, p. 39) 2 . 
Gorz está valorizando, assim, a apreensão da realidade do mundo do trabalho por meio do cotidiano operário no interior da empresa, no contexto do espaço da fábrica, a partir das formas de controle que são exercidas sobre a força de trabalho, de um lado, e da resistência e/ou integração ao controle capitalista pelos trabalhadores, de outro; ao mesmo tempo buscando captar o movimento da classe, suas formas de organização, tanto formais quanto informais, e observando como realmente se dá o conflito no interior da empresa. Em outras palavras, como os trabalhadores enfrentam as condições vivenciadas dentro da fábrica, como se dá a sua experiência no local de produção, bem como as estratégias que podem ser utilizadas pelo operariado na relação com o patronato.

No entanto, ao mesmo em que tempo que o estudo da vivência na fábrica é fundamental para compreendermos a classe operária em seu movimento, é importante ver também a relação dessa classe com outras classes, ou seja, a sua relação com a sociedade, fora dos muros das fábricas.

Vale dizer, para apreendermos o cotidiano operário é necessário vê-lo tanto dentro como fora da fábrica. Thompson, analisando a formação da classe operária inglesa, diz que

[...] as pressões em favor da disciplina e da ordem partiram das fábricas, por um lado, e das escolas dominicais, por outro, estendendo-se a todos os demais aspectos da vida: o lazer, as relações pessoais, a conversação e a conduta. Juntamente com os instrumentos disciplinares das fábricas, das igrejas, das escolas, dos magistrados e dos militares, havia outros meios semioficiais para se impor um comportamento moralizado e disciplinado" (Thompson, 1987, p. 292).

O cotidiano operário é permeado principalmente pela vida na fábrica, em seu local de trabalho. Para grande parte do operariado, o não trabalho, por exemplo, não representa necessariamente o momento do lazer. Esse tempo livre é utilizado principalmente para reorganizar as forças físicas para enfrentar o novo dia de trabalho. O tempo do não trabalho é o mesmo dedicado ao descanso físico. "A vida cotidiana é, em grande medida, heterogênea; e isso sob vários aspectos, sobretudo no que se refere ao conteúdo e à significação ou importância de nossos tipos de atividade. São partes orgânicas da vida cotidiana: a organização do trabalho e da vida privada, os lazeres e o descanso" (Heller, 1972, p. 18). Ainda, segundo a autora, na época pré-histórica, "o trabalho ocupou um lugar dominante nessa hierarquia; e, para determinadas classes trabalhadoras (para os servos, por exem- 
plo), essa hierarquia se manteve, ainda, durante muito tempo; toda a vida cotidiana se constituía em torno da organização do trabalho. À qual se subordinavam todas as demais formas de atividade" (Idem).

O operário fabril de nossos dias, assim como o servo exemplificado por Heller, também vive seu cotidiano profundamente absorvido "pela organização do trabalho", à qual todas as outras atividades estão subordinadas.

A contradição entre tempo livre e trabalho, a oposição entre trabalho e vida foi criada como advento do capitalismo, mais precisamente com a industrialização. Anoção do tempo é completamente modificada com o surgimento da sociedade capitalista. Segundo Thompson, as sociedades industriais distinguem-se como tais em função da maneira como administram o tempo e pela divisão entre trabalho e vida (cf. Thompson, 1979, p. 288).

Referindo-se ainda à questão do tempo, esse autor afirma:

[...] os patrões ensinaram à primeira geração de operários industriais a importância do tempo; a segunda geração formou comitês de jornada curta no movimento pelas dez horas; a terceira fez greves para conseguir horas extras e jornada e meia. Aceitaram as categorias de seus patrões e aprenderam muito bem a lição de que o tempo é ouro" (Idem, pp. 279-280).

Esse processo, no entanto, não se deu sem resistências da classe operária que estava se formando:

[...] a este novo ritmo imposto à vida ordenado pelos patrões, senhores dos relógios [...], o escravo da fábrica reagia nas horas de folga, vivendo na caótica irregularidade que caracterizava os cortiços encharcados de gim dos bairros pobres do início da Era Industrial do século XIX. Os homens se refugiavam no mundo sem hora marcada da bebida ou do culto metodista. Mais aos poucos, a ideia de regularidade espalhou-se, chegando aos operários" (Woodcock, 1998, p. 125).

De certa forma, o itinerário gorziano de volta às origens do movimento operário-na década de 1960-está permeado pelas questões acima sublinhadas.

Não existe uma crise do movimento operário, mas há uma crise da teoria do movimento operário. Esta crise (no sentido de reexame, crítica, ampliação do pensamento estratégico) é devida, principalmente, ao fato de que a reivindicação econômica imediata não mais basta para expressar e concretizar o antagonismo radical da classe operária diante do capitalismo; e de que esta luta, por mais árdua que seja, não é 
mais suficiente para colocar a sociedade capitalista em crise nem afirmar a autonomia da classe operária frente à sociedade na qual se insere" (Gorz, 1968, p. 28).

Para o autor, naquele momento a questão central era a ruptura com o sistema capitalista.

Ao longo do século XX, nos países centrais, a atividade do movimento operário e do sindicalismo guardou estreita relação com o desenvolvimento do capitalismo. As estratégias dos atores do mundo do trabalho estiveram associadas às ações levadas adiante pelo capital, em cada situação concreta. Nos primeiros tempos um embate duro, de classes. De um lado, os setores que buscavam sua inclusão na sociedade da época e, de outro, aqueles que desejavam manter os privilégios, o status quo. Mesmo com diferenças nacionais esse processo, de certa forma, ocorreu até o final dos anos de 1930 e 1940; um segundo momento, em linhas gerais, estendeuse do final da Segunda Guerra Mundial até início dos anos de 1970. É o período de construção do Estado de Bem-Estar Social, que expressava uma aliança "tácita" entre três setores importantes: as grandes empresas, o governo e as centrais sindicais e/ou grandes sindicatos de trabalhadores.

Nesse caso, houve uma ampliação dos direitos sociais, da cidadania, e a real inclusão das classes trabalhadoras na sociedade como um todo, em particular na sociedade de consumo. É o período em que grande parte dos países europeus acompanha a chegada ao poder dos partidos socialdemocratas que possuíam, à época, ampla base de apoio junto ao operariado.

Os anos de 1970, no entanto, desestruturam parte do arcabouço anterior do contrato social e mudaram a configuração na qual os atores sociais atuavam. Essas transformações resultaram no aparecimento de novas formas de organização da produção nas empresas e mudanças substanciais na composição das classes trabalhadoras, e trouxeram impactos relevantes para as relações de trabalho: os sindicatos perderam, em termos relativos e absolutos, um número significativo de aderentes e, de outra parte, houve uma acentuada diminuição do conflito industrial nos países capitalistas centrais.

O mundo do trabalho está vivendo uma profunda transformação nestes últimos quarenta anos. É possível que estejamos assistindo a uma mutação tão significativa quanto aquela que foi palco o século XIX, com os impactos trazidos pela Revolução Industrial (cf. Munck, 2002; Waterman, 1999; Castells, 2000). E, por essa razão, as questões presentes na ação do movimento operário e do sindicalismo, atualmente, são distintas dos temas que se apresentavam para a ação do trabalho organizado no pós-guerra. 
Uma primeira meta das alternativas políticas a ser liberada será destruir o muro que separa o produtor de seu produto e leva o trabalhador, como consumidor mistificado, à contradição consigo mesmo, como produtor alienado. As reivindicações imediatas dos trabalhadores referentes aos salários, horários, ritmos e qualificações, oferecem aos sindicatos, e sobretudo às seções de empresa dos partidos da classe operária, ocasião de indagar sobre o problema da utilidade social e individual de produções às quais o trabalho está vinculado (Gorz, 1968, p. 81).

Esta passagem de Gorz, de certa forma, resume o espírito de seu livro. Uma crítica contundente à sociedade capitalista e uma tentativa de construir uma alternativa a esta. Projeto que passaria por "alcançar a constituição de um poder operário no nível das empresas, dos ramos e, finalmente, da própria economia nacional" (Idem). Neste caso, as premissas presentes em seu trabalho são aquelas que dão conta do fetichismo da mercadoria, do estranhamento, da alienação como analisados na obra de Marx.

Naquele momento, diante das novas configurações do capitalismo que Gorz chama de neocapitalismo, expressão do arranjo sociopolítico-econômico que desembocou, de um lado, no Estado Social e, de outro, em um corporativismo societário (cf. Schmitter, 1992), particularmente na Europa Ocidental, André Gorz constrói uma saída para as classes trabalhadoras que tem como pressuposto a emancipação pelo trabalho, a partir do local de produção, com vistas a alcançar uma sociedade em que não mais existisse a exploração do homem pelo homem. Qualquer proposta que não levasse em conta a autogestão da produção pelos próprios trabalhadores não teria como resolver o problema da alienação no capitalismo. Nesse período, Gorz "considera o problema do controle operário dos processos de trabalho como um ponto de partida necessário para uma estratégia revolucionária preocupada com o problema da alienação do trabalho" (Silva, 2002, p. 115). Isso porque, ainda que a questão da alienação não estivesse limitada ao local de produção, "é nele que residem suas raízes mais profundas" (Idem).

A proposta apresentada por Gorz em Estratégia operária e neocapitalismo, de reformas revolucionárias ou reformas de estruturas, é uma construção analítica que pressupõe a empresa como o centro do embate entre capital e trabalho e como base da sociabilidade e identidade operárias. A luta por essas reformas 
[...] deve aparecer, em todos os níveis, como uma possibilidade concreta e positiva, realizável sob a pressão das massas: no nível da oficina, pela conquista de um poder operário sobre a organização e relações de trabalho, no nível da empresa, pela conquista de um contrapoder operário concernente à taxa de lucro, o volume e a orientação dos investimentos, a evolução e o nível tecnológico" (Gorz, 1968, p. 68).

Essa visão estava baseada na ideia do trabalho e do mundo do trabalho como categoria explicativa fundamental para as sociedades contemporâneas. É, no entanto, esse arcabouço mais geral, no qual estava baseada a teoria e que tinha o trabalho assalariado e suas contradições como tema central para a compreensão do mundo em que vivemos, que nos dias atuais se tornou sociologicamente problemático e que, de certa forma, foi colocado em xeque pelas transformações ocorridas nos últimos decênios (cf. Offe, 1989).

É verdade que o sindicalismo, mesmo vivendo mundialmente uma situação defensiva, bem diferente daquela que era a norma até meados dos anos de 1970, no nível da empresa, dadas certas condições, discute/negocia o tema da participação nos lucros e nos resultados, nas orientações dos investimentos, em alguns casos, notadamente no âmbito da cidade ou da região onde o sindicato está estabelecido, bem como o tema da tecnologia. No entanto, no horizonte do movimento operário ou do sindicalismo atualmente - o móvel de sua luta é menos a busca pelo controle da produção e pela emancipação socialista a partir do local de trabalho e mais a tentativa de inclusão na chamada sociedade de consumo.

As reflexões trazidas por André Gorz em seu livro Estratégia operáriae neocapitalismo retratam aquele momento, os anos de 1950 e 1960, quando os sindicatos nos países centrais são institucionalizados e legitimados no bojo de um arranjo político que tem como premissa o aumento do poder e a consolidação das representações trabalhistas e, como consequência, o Estado Social. Isso tudo, em larga medida, é passado: nas últimas décadas, as grandes organizações industriais, que representavam a força do trabalho organizado, foram aos poucos perdendo força, enfraquecendo sua capacidade de confrontação, de negociação com o capital. Competição global, recessão e incertezas econômicas crescentes trouxeram resultados devastadores para a instituição sindical (cf. Martins Rodrigues, 1999; Western, 1999).

Fica então imediatamente evidente que lutar para que a vida conserve um sentido é lutar contra o poder do capital, e que essa luta deve passar, sem solução de continuidade, do plano da empresa para o plano da sociedade, do plano sindical para o plano 
político, do plano técnico para o plano cultural. Cabe então ao movimento socialista tomar fôlego e situar o combate no seu verdadeiro terreno: a luta pelo poder. Tudo a partir de então é posto em jogo: os empregos, os salários, as carreiras, a cidade, a região, a ciência, a cultura, a possibilidade de desenvolver as capacidades dos indivíduos [...]. Tudo isso só pode ser salvaguardado ou reconquistado se o poder de decisão passar das mãos do capital para as mãos dos trabalhadores (Gorz, 1968, p. 111).

O mundo do trabalho nos dias de hoje guarda uma considerável distância das principais teses expostas por Gorz em Estratégia operária. Ainda que existam setores no interior do movimento dos trabalhadores que mantenham "a chama acesa" dos temas propostos por Gorz, em sua esmagadora maioria, no entanto, o movimento sindical e parcelas ponderáveis das tendências políticas com alguma ligação com as classes trabalhadoras - na sociedade contemporânea - parecem preferir, para parafrasear Gramsci, a guerra de trincheiras à tomada do Palácio do Inverno; a defesa dos direitos já adquiridos nos países de capitalismo maduro e que foram solapados pelos ventos neoliberais nos anos de 1970 e na década de 1980 à luta pela defesa do "poder operário". Não vivemos mais os tempos da Guerra Fria, do mundo bipolar, das certezas incontestes. Tudo isso ficou pelo caminho. O que se assiste hoje é um processo irreversível de transformações nos âmbitos político, social e econômico, que deitou por terra o arcabouço institucional que fora criado com o fim da Segunda Guerra Mundial e que colocou em xeque o chamado compromisso fordista. Outros são os tempos, outras são as questões. Nesse sentido, é possível dizer que este livro de André Gorz é uma obra que caracteriza uma abordagem sociopolítica que se fazia presente em amplos setores da esquerda revolucionária à época, e que mobilizou corações e mentes, atingindo seu ápice no maio francês de 1968.

É importante, no entanto, situar o livro no âmbito do debate intelectual da década de 1960. O próprio autor modifica completamente sua análise sobre a classe operária, a sociedade capitalista e as possibilidades de uma revolução socialista no modelo em que havia sido pensado em Estratégia operária e neocapitalismo quando escreve Adeus ao proletariado. Aqui, já é outro momento histórico, em que a tecnologia da informação parecia ser a miríade do futuro. Além disso, diante das profundas mudanças ocorridas na sociedade capitalista, Gorz já não vislumbra a estratégia socialista de reformas revolucionárias que tinha como agentes o operário no local de trabalho, o partido e o sindicato. Nesse caso, a inflexão do pensamento do autor vai 
levá-lo a recontextualizar o lugar da política e, nesse novo espaço, o proletariado já não seria o portador do futuro, o agente fundamental da transformação social, o sujeito da emancipação. Mas isso já é outra história.

\section{Referências Bibliográficas}

AglietTA, Michel. (1991), Regulación y crisis del capitalismo. México, Siglo Veintiuno. Amorim, Henrique. (2006), “Continuidades e rupturas teóricas em André Gorz: classe social, trabalho e qualificação profissional”. In: SiLVA, Josué Pereira \& RodRIGUES, Iram Jácome. André Gorz e seus críticos. São Paulo, Annablume.

CAstells, Manuel. (2000), A sociedade em rede. São Paulo, Paz e Terra.

Gorz, André. (1968), Estratégia operária e neocapitalismo. Rio de Janeiro, Zahar. . (1982), Adeus ao proletariado. Rio de Janeiro, Forense Universitária.

Heller, Agnes. (1972), O quotidiano e a história. Rio de Janeiro, Paz e Terra.

Martins Rodrigues, Leôncio. (1999), Destino do sindicalismo. São Paulo, Edusp.

Munck, Ronaldo. (2002), Globalisation and Labour. London/New York, Zed Books. Offe, Claus. (1989), Capitalismo desorganizado. São Paulo, Brasiliense.

QueIroz, José Benevides. (2006), “Sociedade e estrutura de classe no neocapitalismo (1950/1960)”. In: SiLvA, Josué Pereira \& RodRigues, Iram Jácome (orgs.), André Gorze seus críticos. São Paulo, Annablume.

RodRigues, Iram Jácome. (2006), “Transformações no mundo do trabalho e dilemas do sindicalismo”. In: Silva, Josué Pereira \& Rodrigues, Iram Jácome (orgs.), André Gorz e seus críticos. São Paulo, Annablume.

Schmitter, Philippe C. (1992), “Continúa el siglo del corporativismo?”. In: Schmitter, Philippe C. \& Lehmbruch, Gerhard. Neocorporativismo I. Más allá del Estado y el mercado. México, Alianza Editorial.

Silva, Josué Pereira da. (2002), André Gorz: trabalho e política. São Paulo, Annablume/Fapesp.

Sturmthal, Adolf. (1971), Consejos obreros. Barcelona, Fontanella.

Thompson, Edward. (1979), "Tiempo, disciplina de trabajo y capitalismo industrial". In: . Tradición, revuelta y consciencia de clase. Barcelona, Crítica.

. (1987), A formação da classe operária inglesa. Rio de Janeiro, Paz e Terra, vol. 2.

Waterman, Peter. (1999), “A New Union Model for a New World Order”. In: MuncK, Ronaldo \& Waterman, Peter. Labour Worldwide in the Era of Globalization. London, Macmillan Press.

WESTERn, Bruce. (1999), Between Class and Market: postwar unionization in the capitalist democracies. Princeton, Princeton University Press. 
Woodcock, George. (1998), “A ditadura do relógio”. In: Woodcock, George (org.), Os grandes escritos anarquistas. Porto Alegre, LPM.

Resumo

\section{Estratégia operária e neocapitalismo}

O objetivo deste texto é discutir algumas das questões propostas por André Gorz em seu livro Estratégia operária e neocapitalismo, publicado em meados da década de 1960, e situar este trabalho como parte de um conjunto mais amplo de estudos do autor em que a questão das transformações no capitalismo, nos países centrais, pós-Segunda Guerra Mundial, teria colocado a necessidade de novas estratégias para a ação do movimento operário e do sindicalismo. Um primeiro tema seria a relação entre as reivindicações mais gerais e aquelas mais específicas, e o papel desempenhado pelas demandas de tipo reformista na ação trabalhista; um segundo aspecto seria refletir, a partir dessa nova fase, à época, sobre os estudos de André Gorz acerca das mudanças mais gerais no âmbito do capitalismo e, por extensão, das sociedades capitalistas mais desenvolvidas; um terceiro aspecto, e que analisaremos mais detidamente, diz respeito à questão do local de trabalho, da empresa, da fábrica, da produção como locus fundamental da luta pela emancipação dos trabalhadores.

Palavras-chave: Estratégia operária; Neocapitalismo; Sindicalismo; Socialismo.

\section{Abstract}

Working-class strategy and neocapitalism

This text discusses some of the questions raised by André Gorz in his book Workingclass strategy and neocapitalism, published in the mid 1960s. It situates this work as part of a wider set of studies by the author in which he explores the transformations in capitalism in central countries after the Second World War, focusing on how these

Texto recebido e aprovado em 24/3/2009.

Iram Jácome Rodrigues é professor livredocente do Departamento de Economia e do Programa de PósGraduação em Sociologia da Universidade de São Paulo e pesquisador do CNPq. Email: ijrodrig@usp.br. prompted the need for new action strategies among the working-class and union movements. The first theme discussed is the relationship between general and specific demands and the role performed by reformism in working-class action. Secondly, based on this new phase, the article reflects on André Gorz's studies concerning overall changes within capitalism and, by extension, within the more developed capitalist societies. Finally, the article analyzes in more detail the question of the workplace, company, factory and production as a fundamental locus in the fight for working-class emancipation.

Keywords: Working-class strategy; Neocapitalism; Unionism; Socialism. 